\title{
Effect on Insulin upon Storage in Extreme Climatic Conditions (Temperature and Pressure) and Their Preventive Measures
}

\author{
Girish Khurana ${ }^{1}$ Vipul Gupta² \\ ${ }^{1}$ Department of Medicine, Vidya Medicare Centre, Bahadurgarh, India \\ 2 Department of Medicine, Gupta Ultrasound and Heart Care \\ Centre, Paschim Vihar, New Delhi, India
}

\author{
Address for correspondence Girish Khurana, MD, Department of \\ Medicine, Vidya Medicare Centre, Bahadurgarh, India \\ (e-mail: vmcentre@gmail.com).
}

\begin{abstract}
Keywords

- insulin

- climatic changes

- therapeutic efficacy

Insulin is a naturally occurring hormone secreted by the pancreas. Insulin is required by the body cellsto remove and use glucose from the blood. The insulin and its various analogues are essential in management of type 1 diabetes mellitus. This study has been done to analyze how variation in various storage conditions and climatic changes causes change in therapeutic efficacy. Storage condition affects the stability of insulin as observed in a study in which insulin stored at temperature between 32 and $37^{\circ} \mathrm{C}$ showed 14 to $18 \%$ decrease in its potency and could not cause a significant decrease in blood sugar level when compared with those receiving insulin stored at $5^{\circ} \mathrm{C}$. This work was done with the aim of finding the effect of climatic changes and storage condition on efficacy of insulin.
\end{abstract}

\section{Introduction}

\section{Insulin}

Insulin is a naturally occurring hormone secreted by the pancreas. Insulin is required by the body cellsto remove and use glucose from the blood. Cells use glucose to produce energy that they need to carry out their functions. Researchers first gave an active extract of the pancreas containing insulin to a young diabetic patient in 1922, and the Food and Drug Administration (FDA) first approved insulin in 1939. Currently, insulin used for treatment is derived from beef and pork pancreas as well as recombinant (human-made) technology. The first recombinant human insulin was approved by the FDA in 1982. People with diabetes mellitus (DB) have a reduced ability to take up and use glucose from the blood, and as a result, the glucose level in the blood rises. In type 1 diabetes, the pancreas cannot produce enough insulin. Therefore, insulin therapy is required. In type 2 diabetes, patients produce insulin, but cells throughout the body do not respond normally to the insulin. Nevertheless, insulin also may be used in type 2 diabetes to overcome the resistance of the cells to insulin. By increasing the uptake of glucose by cells and reducing the concentration of glucose in the blood, insulin prevents or reduces the long-term complications of diabetes, including damage to the blood vessels, eyes, kidneys, and nerves. Insulin is administered by injection under the skin (subcutaneously). The subcutaneous tissue of the abdomen is preferred because absorption of the insulin is more consistent from this location than subcutaneous tissues in other locations. ${ }^{1-3}$

\section{Effect of Temperature on Insulin}

Insulin being a protein is liable to get denatured. Insulin due to its colloidal nature is highly prone to precipitation induced by changes in the environmental $\mathrm{pH}$ and temperatures. Instability in the proteins is attributed to the differential level of changes in the protein structure. This happens when exposed to variable physicochemical changes in the environment. Insulin is very sensitive to sunlight and extreme temperatures resulting in its degradation. Degradation can be broadly of two types: physical and chemical. Physical degradation (e.g., aggregation, adsorption, etc.) occurs when the physical state of the protein undergoes irreversible changes without any change in its covalent structure. In contrast, chemical degradation refers to a change in the covalent structure of the protein. The relative susceptibility of insulin analogues to undergo chemical degradation depends on their received

March 6, 2019

accepted

March 11, 2019
DOI https://doi.org/

10.1055/s-0039-1692371

ISSN 2321-0656.
(C)2019 Novo Nordisk Education Foundation
License terms

(요 (1) $\odot \circledast$ 
thermodynamic property and tendency to undergo transient conformational changes. Both physical and chemical degradations could result in loss of bioactivity of insulin. Hence un-opened vials of insulin have to be stored in a controlled environment of 2 to $8^{\circ} \mathrm{C}$ in a refrigerator protected from light. In a pilot study conducted in JIPMER, Puducherry, by Gitanjali et al, it was found that among 131 diabetic patients, $59 \%$ of them had hyperglycemia, indicating poor glycemic control. Out of these hyperglycemic patients, $56 \%$ were storing the insulin vials at room temperature.

\section{Recommendation of Storage Conditions}

Also, the manufacturer recommendations on the storage and shelf life of opened insulin vial are different among different companies. Eli lily (Gurgaon, India) recommends that opened insulin vials can be stored either refrigerated $\left(2-8^{\circ} \mathrm{C}\right)$ or at room temperature less than $30^{\circ} \mathrm{C}$, without losing biological activity for a period of 31 days. According to Novo Nordisk, (Bangalore, India) and Biocon (Bangalore, India) opened vials can be stored for a period of 6 weeks, when stored at room temperature not more than $25^{\circ} \mathrm{C}$ and should not be refrigerated. Exposure to higher temperatures other than that recommended during storage as well as while using may degrade insulin by hydrolysis or other mechanisms. Even short periods of exposure of insulin to higher temperatures can cause adverse effects that aggravate the challenges caused by interruption in the cold chain of delivery, distribution, and storage. Exposure to light and high temperatures results in insulin degradation, which leads to formation of transformation products (deaminated insulin, covalent dimers, and higher oligomers) and increased fibril formation, which is a potential cause of loss in biological potency. ${ }^{4-6,7}$ The measure of activity of insulin expressed in terms of the amount required to produce a defined effect (reduction in blood glucose) is called the potency of insulin. It is affected by exposure to light, temperature, and vibration. Inappropriate storage of insulin can also decrease insulin's potency, which could contribute to poor response to the insulin. A case report published in British Medical Journal (2009) by Pryce described a case of an 11-year-old girl on insulin pump who presented with diabetic ketoacidosis (DKA) because of reduced potency of insulin on exposure to heat and sunlight. A study done by Gitanjali et $\mathrm{al}^{7}$ in Puducherry, India, where insulin concentration was measured by HPLC, showed a decrease in the concentration of regular insulin in vials and biphasic formulations by 14 to $18 \%$ and 11 to $14 \%$, respectively, in vials stored at $32^{\circ} \mathrm{C}$ and $37^{\circ} \mathrm{C}$ when stored for 28 days. There was a considerable reduction in the blood glucose with respect to basal glucose at 15,30 , and 60 minutes after insulin injection in rats, but there was no significant reduction in the blood glucose levels in the animals injected with insulin stored at $32^{\circ} \mathrm{C}$ and $37^{\circ} \mathrm{C}$ with respect to that stored at $5^{\circ} \mathrm{C}$. Most of the insulin stability studies are from western countries where the room temperature is usually within $25^{\circ} \mathrm{C}$. In many places in India during summer season, the temperature rises beyond $35^{\circ} \mathrm{C}$ and certain times beyond $40^{\circ} \mathrm{C}$. The patients from the rural areas who lack the facility to store insulin in the refrigerator are advised by the health professionals to store it in a mud pot where the inside temperature will be a few degrees lower than the room temperature, to provide a near ideal storage environment for insulin to maintain the stability as far as possible. However, during summers, as the room temperature rises, the pot temperature also may rise above $25^{\circ} \mathrm{C}$ or even beyond $35^{\circ} \mathrm{C}$. Therefore, even the insulin stored in a mud pot is not protected from denaturation due to high temperatures during summer. This could be one of the reasons why some patients require comparatively higher doses of insulin and show clinical symptoms of drug resistance. ${ }^{8-18}$ To attain maximum effect of insulin, one must know the ideal storage condition and how to preserve the insulin. For the people with diabetes who use it, insulin is a vital need. It is important to store insulin as directed, so that it remains usable by those who need it. Follow these tips to ensure effective insulin storage..$^{19,20}$

\section{Protective Measure to Maintain the Shelf Life of Insulin}

1. Keep it cool: According to the product labels from all three U.S. insulin manufacturers, it is recommended that insulin be stored in a refrigerator at approximately 36 to $46^{\circ} \mathrm{F}$. If you are using ice, avoid freezing the insulin. Do not use insulin that has been frozen.

2. Know its expiration date: Unopened insulin refrigerated in the ranges described above maintains potency until the expiration date on the package.

Insulin products contained in vials or cartridges supplied by the manufacturers (opened or unopened) may be left unrefrigerated at a temperature between 59 and $86^{\circ} \mathrm{F}$ for up to 28 days and continue to work. However, an insulin product that has been altered for the purpose of dilution or by removal from the manufacturer's original vial should be discarded within 2 weeks. Insulin contained in the infusion set of a pump device (e.g., reservoir, tubing, catheters) should be discarded after 48 hours. Insulin contained in the infusion set of a pump device and exposed to temperature exceeding $98.6^{\circ} \mathrm{F}$ should be discarded.

\section{Effect on Insulin on Temperature Extremities (Hot and Cold)}

Insulin loses some effectiveness when exposed to extreme temperatures. The longer the exposure to extreme temperatures, the less effective the insulin becomes. This can result in loss of blood glucose control over time. Keep insulin away from direct heat and out of direct sunlight. Under emergency conditions, you might still need to use insulin that has been stored above $86^{\circ} \mathrm{F}$. When properly stored insulin becomes available again, the insulin vials that have been exposed to these extreme conditions should be discarded and replaced as soon as possible. Elevated temperature in countries such as the African continents can severely degrade the insulin. According to findings by Mjota in Kenya 2008, there is a small proportion of patients storing insulin by refrigerators due to poverty The cultural practices and socioeconomic 
and political challenges that unsettle people make most DM patients to live in very pathetic housing conditions, street families in particular. This makes correct home storage practice of insulin to be practically impossible for the low-income earners and the poverty-stricken class that constitutes about $70 \%$ of the urban population. The effect of storing insulin in suboptimal conditions is a commonplace for the majority of insulin using DM patients in urban Kenya, which goes a long way in the effectiveness of therapy being suboptimal. Most insulin users from a low economic class use pot with sand in water contraptions from a random survey on storage in sub-Saharan region medical outpatient clinics. Twenty-six to 77\% DM patients have refrigerators for storing insulin. Insulin outside the refrigerator should be kept cool within 12 to $30^{\circ} \mathrm{C}$; it should not be allowed to freeze. If stored between 2 and $8^{\circ} \mathrm{C}$, it will remain stable until the expiry date. According to Garry Gilles 2009 clinical review, insulin used daily should be kept at room temperature and remains potent and stable for 28 days also comfortable for injection. However, it is good to have extra supply of insulin in the refrigerator as a buffer stock for any eventuality of loss of potency, damage, or loss. Most physicians are not aware of the real effectiveness of insulin once it is opened. Also, three pharmaceutical companies that supply insulin reveal different storage indications for every type 9 of insulin they produce, depending on the particular formulation, method of manufacture, its container, and ambient storage conditions. The storage of unopened vials, cartridges, or prefilled insulin delivery systems should be done at recommended temperatures, so that they can be used until the expiration date Insulin. In-use insulin can be kept nonrefrigerated for up to 28 days away from direct heat and light, at controlled room temperature. ${ }^{21-24}$

\section{Challenges of Insulin Storage in Cold Climatic Conditions}

The diabetes pandemic knows no geographical boundaries. Along with modernization, diabetes has reached the remote areas such as Himalayan areas of Lahaul-Spiti (cold desert) and Kinnaur, in the Indian state of Himachal Pradesh, located in the upper region of the Western Himalayas. Inhabited predominantly by the tribal population, this district is located at an altitude of 8,000 to $16,000 \mathrm{ft}$ above sea level. The unique geographic conditions and far and scarce medical service impose great challenges for the management of diabetes in this part of the world. Dietary patterns, which include drinking of copious amounts of liquor, locally distilled from barley, dependence on local nonvegetarian foods, and scarce availability of fruits and vegetables, go against routine diabetes diet prescriptions.

These tribal areas remain cutoff from rest of the country at least for 3 to 4 months in the winters with interrupted supply of electricity. People with diabetes usually seek specialized diabetic care from the state capital, located 250 to $500 \mathrm{~km}$ away (16-24 hours drive through one of the most treacherous roads in the world). The challenges posed by diabetes on the top of the world have been addressed innovatively.

Three patients from tribal areas living at an "altitude" of 9,500; 12,000; and 14,500 ft at a distance of 250 and $450 \mathrm{~km}$ from the state capital were prescribed insulin for uncontrolled blood glucose. The unique geographic condition of these areas, and peculiar social habits and dietary patterns of the inhabitants, imposes unique challenges for the use of insulin in this part of the world. Besides having the danger of hypoglycemia, however, the biggest challenge remains how to store insulin in the winter when outside temperature dips to $-30^{\circ} \mathrm{C}$ mostly during midnight and inside temperature of the living room goes up to 40 to $70^{\circ} \mathrm{F}$ due to constant burning of "Bukhari" made up of iron. Difficulty in access and storage of insulin creates a need for crafting a locally relevant, improvised solution for the same. In winters, people of these areas wear warm clothes made up of sheep and yolk wool to protect from severe cold. One such unique cloth people wear in the winter is an abdominal binder, which measures 2 to $3 \mathrm{ft}$ in width and 5 to $15 \mathrm{ft}$ in length. Seeing a woman wearing the traditional attire in a hospital, an innovative idea of insulin storage that was "locally" relevant and easily acceptable struck in mind: "It was thought to store insulin in multiple layers of abdominal binder, which prevents it from freezing in winter" and was discussed with patients on their follow-up visit. They were advised to wrap the insulin vials and/or pens in "multiple layers" in the abdominal binder (where the temperature recorded was between 5 and $10^{\circ} \mathrm{C}$ )

The success of this practice was evident from the normal $\mathrm{HbA}_{1 \mathrm{C}}$ values and the smiles on their faces, when they visit state capital for routine medical consultation. Normally, we think of people living with diabetes at normal altitude, not of those living in the extreme conditions of the world; one like those living "in the Himalayas" and this improvised method of insulin storage may be of great value for those diabetic patients living at the top of the world( $\sim$ Fig. 1).

As the recent cold waves in North America and Europe show, no part of the world is immune to extremes of temperature. Best practice sharing is required between people living with, and caring for, diabetes, in other, similarly inhospitable regions of the world, to help improve the quality of care. ${ }^{25-28}$

\section{Changes in the Atmospheric Pressure}

Changes in atmospheric pressure that occur during airplane travel may lead to insulin pumps unintentionally delivering insulin while flying, as per recent data. After becoming aware of 50 cases in which patients with type 1 diabetes using insulin pumps developed recurrent hypoglycemia during commercial air travel, researchers in Australia sought to investigate the effect that atmospheric pressure has on insulin pumps. They included five Animas 2020 pumps (IR1200/2020) and five Medtronic Paradigm pumps (1.8 mL cartridge) with $60-\mathrm{cm}$ infusion systems in their analysis.

\section{Effect of Pressure Changes}

To gauge the effect that changes in pressure may have in the pumps, the researchers conducted a hypobaric chamber study in which they mimicked normal flight in a commercial airliner, as well as abnormal flight with catastrophic decompression. Results revealed that during ascent, from 760 to 


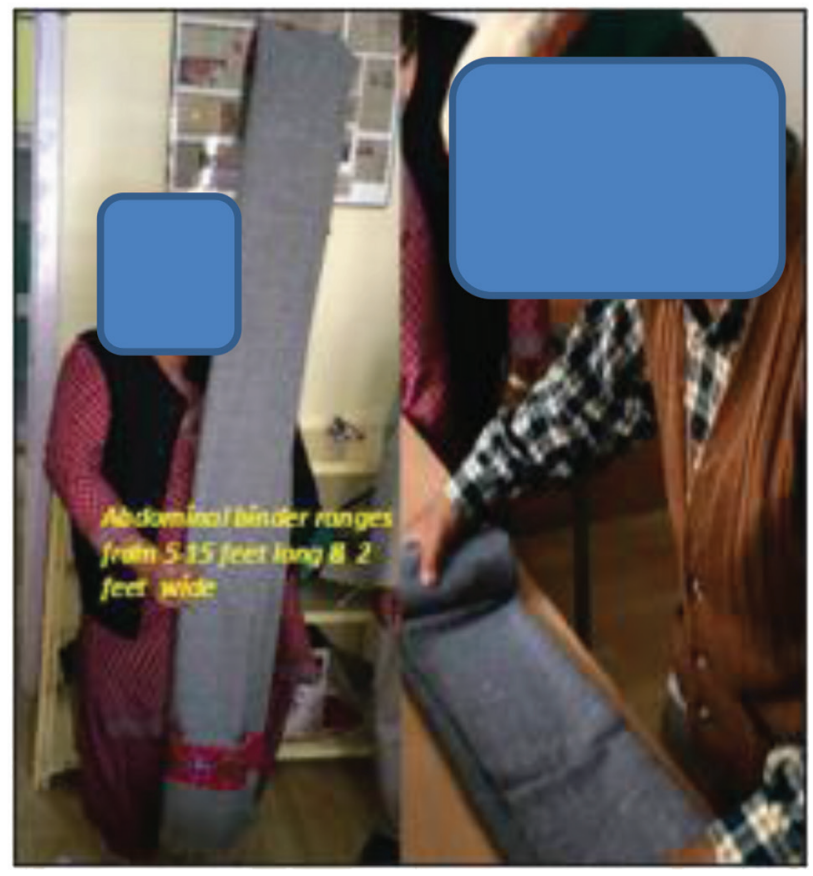

Fig. 1 Abdominal binder used for the protection of Insulin.

$560 \mathrm{~mm} \mathrm{Hg}$, the Animas pumps delivered 0.776 excess units of insulin $(p<0.000001)$, whereas the Medtronic pumps delivered 0.709 excess units of insulin $(p<0.000001)$. During descent, from 560 to $760 \mathrm{~mm} \mathrm{Hg}$, the pumps delivered 0.663 units less than expected and the Medtronic pumps delivered 0.533 units less than expected, as per the researchers. Catastrophic depressurization, a decrease in pressure from 760 to $260 \mathrm{~mm} \mathrm{Hg}$ during 1 minute, however, led to the delivery of more than eight excess units due to plunger movement. In a second pressure study, the researchers examined the pumps' insulin delivery during actual flight of a Boeing 767-338. Findings from this analysis showed that Animas pumps delivered 1.37 units of excess insulin $(0.685 \%$ of cartridge volume; $p<0.001$ ) and Medtronic pumps delivered 1.01 units of excess insulin $(0.561 \%$ of cartridge volume; $p<0.001$ ) during ascent. In contrast, during descent, insulin appeared to be sucked back into pumps, leading to deficits of 0.87 and 0.58 units of insulin for Animas and Medtronic pumps, respectively. The researchers also performed a bubble study in which they found gas bubbles in all syringes after $50-\mathrm{mm} \mathrm{Hg}$ decreases in pressure. Bubbles disappeared after an atmospheric pressure of $760 \mathrm{~mm} \mathrm{Hg}$ was restored. Changes in bubble size were consistent with Boyle's law, they said. Plunger movement was also examined. According to the researchers, the Animas cartridge plunger moved after a $273.48-\mathrm{mm} \mathrm{Hg}$ decrease in pressure. Because of their findings, the researchers said the insulin pump cartridge should contain only $1.5 \mathrm{~mL}$ of insulin, and patients should disconnect the pump before takeoff. When at cruising altitude, remove the cartridge from the pump and ensure that there are no air bubbles before reconnecting. After landing, disconnect the pump, prime the line with two units, and then reconnect. If cabin decompression occurs, disconnect the pump.

\section{Conclusion}

It could be thus concluded that insulin is a lifesaving therapy in management of DM type 1. Insulin has to be stored with caution as extremes of temperature or change in altitude can lead to its decomposition and reducing its efficacy.

\section{Conflict of Interest}

None declared.

\section{References}

1 Sonksen P, Sonksen J. Insulin: understanding its action in health and disease. Br J Anaesth 2000;85(1):69-79

2 Koeslag JH, Saunders PT, Terblanche E. A reappraisal of the blood glucose homeostat which comprehensively explains the type 2 diabetes mellitus-syndrome X complex. J Physiol 2003;549(Pt 2):333-346

3 Ahmad K. Insulin sources and types: a review of insulin in terms of its mode on diabetes mellitus. J Tradit Chin Med 2014;34(2):234-237

4 Camacho-Amor ML, Morales-Romo A, Calvo A, et al. [Evaluation of the cold chain during the national antipoliomyelitis vaccination days. Mexico, 1987-1988] [in Spanish] Salud Publica Mex 1990;32(1):43-51

5 Brown LH, Krumperman K, Fullagar CJ. Out-of-hospital medication storage temperatures: a review of the literature and directions for the future. Prehosp Emerg Care 2004;8(2): 200-206

6 Grajower MM, Fraser CG, Holcombe JH, et al. How long should insulin be used once a vial is started? Diabetes Care 2003;26(9):2665-2666

7 Vimalavathini R, Gitanjali B. Effect of temperature on the potency \& pharmacological action of insulin. Indian Journal of Medical Research. 2009;130(2): 166-169

8 Gregory R, Edwards S, Yateman NA. Demonstration of insulin transformation products in insulin vials by high-performance liquid chromatography. Diabetes Care 1991;14(1):42-48

9 Kumar KMP, Bhat GK. Animal insulins-current status. Int J Diabetes Dev Countries 2003;23:6-9

10 Adams PS, Haines-Nutt RF, Town R. Stability of insulin mixtures in disposable plastic insulin syringes. J Pharm Pharmacol 1987;39(3):158-163

11 Chandler C, Gryniewicz CM, Pringle T, Cunningham F. Insulin temperature and stability under simulated transit conditions. Am J Health Syst Pharm 2008;65(10):953-963

12 Tarr BD, Campbell RK, Workman TM. Stability and sterility of biosynthetic human insulin stored in plastic insulin syringes for 28 days. Am J Hosp Pharm 1991;48(12):2631-2634

13 Insulin. Indian Pharmacopoeia. Ministry of Health and Family Welfare, Government of India, New Delhi, India: Controller of Publications; 1996;:399-401

14 Yin W, Yuan Z, Tsutsumi K, et al. A lipoprotein lipase-promoting agent, NO-1886, improves glucose and lipid metabolism in high fat, high sucrose-fed New Zealand white rabbits. Int J Exp Diabesity Res 2003;4(1):27-34

15 Georgiev IP, Kanelov IN, Dimitrova SS, et al. An experimental model for evaluation of glucose tolerance in rabbit. Bulg J Vet Med 2006;9(1):27-35

16 Pingel M, Vølund A. Stability of insulin preparations. Diabetes 1972;21(7):805-813

17 Storvick WO, Henry HJ. Effect of storage temperature on stability of commercial insulin preparations. Diabetes 1968;17(8):499-502

18 Arya SC. Insulin storage in a clay pot. Ann Saudi Med 2000;20(5-6):491-492 
19 Puepet FH, Mijinyawa BB, Akogu I. Insulin storage by patients with diabetes mellitus in Jos, Nigeria. J Med Trop 2007;9(1): 37-40

20 Vimalavathini R, Agarwal SM, Gitanjali B. Educational program for patients with type-1 diabetes mellitus receiving free monthly supplies of insulin improves knowledge and attitude, but not adherence. Int J Diabetes Dev Ctries 2008;28(3):86-90

21 Garry G. Storing Insulin-What's the Best Way to Store Insulin? [Internet]. [cited October 26, 2015]. Available at:http:// type1diabetes.about.com/od/insulinandmedications/qt/insulin_storage.htm

22 Strauss K, Gols HD, Hannet I, Partanen TM, Frid A. A panEuropean epidemiologic study of insulin injection technique in patients with diabetes. Pract Diabetes Int 2002;19(3):71-76

23 Nathan DM, Bayless M, Cleary P, et al; DCCT/EDIC Research Group. Diabetes control and complications trial/epidemiology of diabetes interventions and complications study at 30 years: advances and contributions. Diabetes 2013;62(12):3976-3986
24 Mullan RJ, Montori VM, Shah ND, et al. The diabetes mellitus medication choice decision aid: a randomized trial. Arch Intern Med 2009;169(17):1560-1568

25 Mokta JK, Kalra S. Insulin storage in the upper Himalayas. Rural Remote Health 2014;14(3):2983

26 Kalra S, Kalra B. Storage of insulin in rural areas. J Acad Med Scim 2012;2:88-89

27 Kalra S, Gupta Y. Insulin technique. Sri Lanka J Diabetes Endocrinol Metab 2015;5:85-90

28 Tandon N, Kalra S, Balhara YP, Baruah MP, Chadha M, Chandalia $\mathrm{HB}$, et al. Forum for injection technique (FIT), India: the Indian recommendations 2.0 , for best practice in insulin injection technique, 2015. Indian J Endocrinol Metab 2015;19:317-331 